\title{
Development of a Human PBBK Model for Mixtures: Trio Mixture of Mercury, Lead, and Selenium
}

\author{
Danjuma D. Maza, Joshua O. Ojo \\ Department of Physics and Engineering Physics, Obafemi Awolowo University, Ile-Ife, Nigeria
}

\begin{abstract}
A physiologically-based biokinetic (PBBK) model has been developed for predicting simultaneously the ADME properties of lead, mercury, and selenium in a number of target tissues of humans. Independent models for mercury, lead and selenium which were developed in a previous study undertaken by us were integrated into a single model for the mixture of these elements. Oral doses were presented in $\mu \mathrm{mol} / \mathrm{kg} / \mathrm{day}$, while tissue concentrations were in $\mu \mathrm{mol} / \mathrm{kg}$. The integration was based on the fact that interaction among these elements affects their bioaccumulation in the respective tissues, resulting in alterations to their partition coefficients. Combined oral doses of mercury and lead were categorized as either low or high, while selenium doses were categorized as either low, adequate or high. With the combined dose of mercury and lead categorized as low, and selenium dose also categorized as low, the concentration of mercury and lead in the liver, kidney, brain, richly perfused tissues, and slowly perfused tissues were modulated by factors of 2.01, 0.91, 1.5, 0.91, and 0.90, respectively, while the concentration of selenium in these tissues were modulated by factors of $0.03,0.21,0.89,0.75$, and 0.75 , respectively. On the other hand, with the combined dose of mercury and lead categorized as high and selenium dose categorized as low, the concentration of mercury and lead in these tissues were modulated by factors of 1.51, 0.68, 1.28, 1.45, and 1.45, respectively, while that of selenium were modified by factors of 0.05, 0.30, 0.45, 0.60, and 0.60, respectively. With adequate selenium intake and combined dose of mercury and lead categorized as high, the concentration of mercury and lead in the various tissues were not modulated, while the concentration of selenium in the liver, kidney, brain, richly perfused tissues, and slowly perfused tissues were modulated by factors of 0.82, 2.89, 0.96, 0.64, and 0.64, respectively.

Keywords : physiologically-based, biokinetic, model, mercury, lead, selenium, interaction
\end{abstract}

\section{Introduction}

In environmental health risk assessment, the internal concentrations of active compounds at their target organs need to be related to the dose to which an animal or human subject has been exposed to $[1,2,3,4]$. Reason being that, both beneficial and adverse effects produced by a chemical substance, in an animal or human subject, are related to the free concentration of the active chemical agent at the target tissue and not the amount of chemical substance at the site of exposure or absorption. Physiologically-based biokinetic models are quite useful tools, in assessing the internal dose at target organs, for a wide variety of exposure scenarios $[5,1,6,7]$. Humans are constantly being exposed to a host of toxic environmental chemicals. Due to interaction between components of chemical mixtures, exposure to multiple chemicals may bring about significant modulation of tissue dose of the toxic moiety of one or more of the individual components of the chemical mixture $[8,9,10]$. Consequently, the toxicity of chemical substances become modified as a result of co-exposure to multiple agents in the environment [10]. Mercury $(\mathrm{Hg})$ and lead $(\mathrm{Pb})$ are known toxic elements, while selenium $(\mathrm{Se})$ has been known to mitigate their toxic effect. It is increasingly becoming evident that the toxicity of these toxic heavy metals is associated with their interaction with selenium [11, 12, 13, 14, 15, 16]. Mercury and lead both have very high affinity for selenium, forming insoluble complexes with selenium. When selenium is bound to either lead or mercury, it becomes unavailable to carry out its essential functions. Because the complexes formed are insoluble, the retention of these elements in various tissues are affected, altering their partition coefficients in the respective organs [8]. The concentration of the elements in the venous blood, $C_{V T}$, exiting a given tissue, T, will be modified as:

$$
C_{V T}=\frac{C_{T}}{Q_{T} P_{T}}
$$

where $\alpha_{T}$ is the modification factor for the partition coefficient, $C_{T}$ and $P_{T}$ are the tissue concentration and partition coefficient. This leads to modifications in the mass balance ordinary differential equations.

Modeling the interactions was predicated on the fact that both mercury and lead have very high affinity $\left(\cong 10^{45}\right)$ for selenium $[12,17,13,11]$. Furthermore, it was assumed that selenium views mercury and lead as identical elements because of the similarity in their mode of interaction with it. Additionally, it was assumed that there is no interaction between mercury and lead. In a study undertaken by Maza and Ojo [18], models for the binary mixtures of $\mathrm{Hg} / \mathrm{Se}$ and $\mathrm{Pb} / \mathrm{Se}$ were developed to provide a platform for viewing the interaction 
between $\mathrm{Hg}$ and $\mathrm{Se}$, and between $\mathrm{Pb}$ and $\mathrm{Se}$. However, it is still needful to develop models for the trio mixture of mercury, lead and selenium to provide a platform for viewing the combined effect of $\mathrm{Hg}$ and $\mathrm{Pb}$ on $\mathrm{Se}$.

\subsection{Model Integration}

\section{Methods}

In our previous study, models for binary mixtures of mercury/selenium and lead/selenium were developed [18]. As part of that study independent models were developed and evaluated for lead, mercury and selenium. In this study, an extension of that work, the independent models were integrated to provide a platform for viewing the combined effect of lead and mercury on selenium. Interaction was modeled primarily for oral ingestion only, due to availability of data.

\subsection{Modifying Partition coefficients}

Integration was predicated on the fact that the interaction between mercury and selenium, and lead and selenium affects the retention of these elements in the respective tissues $[8,14,15]$. Partition coefficients were modified utilizing the result of studies conducted on rats by Ralston and collaborators $[14,15]$ as guide. Modification factors for the partition coefficients of mercury in the brain, liver and kidney compartments, were estimated from the work of Ralston and coworkers $[14,15]$. These were used directly without alteration. The modification factors for the other compartments were assumptions. For each tissue, modification factors to the partition coefficients of mercury and lead were assigned the same value. This is because of the similarity in the mechanism of interaction between mercury and selenium and between lead and selenium.

\subsection{Dose Categorization}

Doses were categorized as shown in Table 1. The combined dose of mercury and lead $(\mathrm{Hg}+\mathrm{Pb}$ dose $)$ were categorized as low $(\leq 0.5 \mu \mathrm{mols} / \mathrm{kg} /$ day $)$ or high $(>0.5 \mu \mathrm{mols} / \mathrm{kg} /$ day $)$. The low dosing states were made to assume the value of 0 , while high dosing states assume the value 1 . On the other hand, selenium doses mere categorized as low $(\leq 1.0 \mu \mathrm{mols} / \mathrm{kg} /$ day $)$, adequate $(>1.0 \leq 5.0 \mu$ mols $/ \mathrm{kg} /$ day $)$, or high $(>5.0 \mu \mathrm{mols} / \mathrm{kg} / \mathrm{day})$. Low, adequate and high dosing states were made to assume values of 0,1 , and 2 , respectively. The dose categorization was used to implement the logic for the integration.

\subsection{Integration Logic}

A Logic circuit (Fig. 1) was designed for each tissue, to facilitate modeling the interaction. The variable $\mathrm{M}$ assumes the value 0 when interactions were not modeled, and the value 1 when interactions were modeled. The variable $\mathrm{HgPb}$ was used to represent the combined $(\mathrm{Hg}+\mathrm{Pb})$ dosing state and assumes values of 0 and 1, corresponding to low and high dosing states respectively. On the other hand, Se represents selenium dosing state and assumes values 0,1 and 2, corresponding to low, adequate and high dose states of selenium respectively. From the logic circuits, truth tables were constructed for each tissue compartment. These were used in implementing the code that modeled the modifications to the partition coefficients. Table 2 shows a typical truth table constructed for the brain compartment. For each element, the mass balance equation for tissues described by perfusion rate-limited kinetics were modified thus:

$$
V_{T} \frac{d C_{T}}{d t}=Q_{T}\left(C_{P A}-\frac{C_{T}}{\mathbb{Q}_{T} P_{T}}\right)
$$

where $\alpha_{T}$ is the modification factor for the partition coefficient of tissue, $T, C_{P A}$ is concentration in arterial plasma, while $C_{T}$ and $P_{T}$ are the concentration and the unmodified partition coefficient of the element in the tissue. Similarly, the modified mass balance equations for tissues, such as bone which are described by permeation rate-limited kinetics were modified as:

$$
\begin{gathered}
V_{T S} \frac{d C_{T S}}{d t}=Q_{T}\left(C_{P A}-C_{T S}\right)-P A_{T}\left(C_{T S}-\frac{C_{T D}}{\mathbb{Q}_{T} P_{T}}\right) \\
V_{T D} \frac{d C_{T D}}{d t}=P A_{T}\left(C_{T S}-\frac{C_{T D}}{\mathbb{Q}_{T} P_{T}}\right)
\end{gathered}
$$

Where $P A_{T}$ is the permeability area cross product for the tissue.

Table 1. Dose Categorization

\begin{tabular}{|c|c|c|c|c|c|}
\hline \multicolumn{3}{|c|}{$(\mathbf{H g}+\mathbf{P b})$ Dose } & \multicolumn{3}{c|}{ Se Dose } \\
\hline $\begin{array}{c}\text { Dose } \\
(\mu \mathrm{mol} / \mathrm{kg} / \text { day })\end{array}$ & Category & Dose state & $\begin{array}{c}\text { Dose } \\
(\mu \mathrm{mol} / \mathrm{kg} / \text { day })\end{array}$ & Category & Dose state \\
\hline$\leq 0.5$ & Low & 0 & $\leq 1.0$ & Low & 0 \\
\hline$>0.5$ & High & 1 & $>1.0 \leq 5.0$ & Adequate & 1 \\
\hline & & & $>5.0$ & High & 2 \\
\hline
\end{tabular}




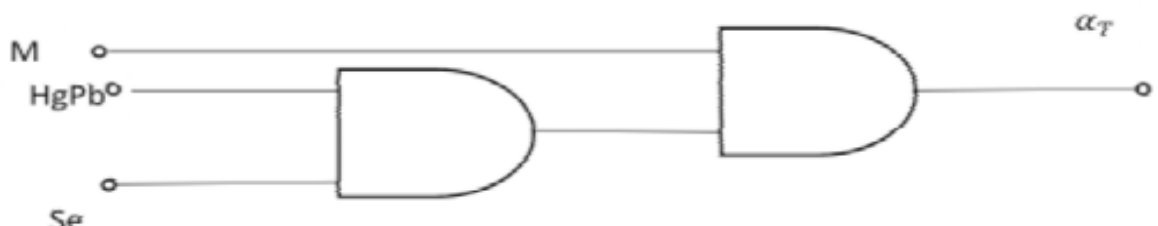

Figure 1. Logic circuit for modeling interaction in respective tissues.

Table 2. Typical truth table for the $\mathrm{Hg} / \mathrm{Pb} / \mathrm{Se}$ mixture model: Truth table for the brain compartment, used to allocate modification factors in accordance with the dose categorization.

\begin{tabular}{|l|l|l|l|}
\hline $\mathbf{M}$ & $\mathbf{H g P b}$ & $\mathbf{S e}$ & $\boldsymbol{\alpha}_{\boldsymbol{B R}}$ \\
\hline 0 & 0 & 0 & 1 \\
\hline 0 & 0 & 1 & 1 \\
\hline 0 & 0 & 2 & 1 \\
\hline 0 & 1 & 0 & 1 \\
\hline 0 & 1 & 1 & 1 \\
\hline 0 & 1 & 2 & 1 \\
\hline 1 & 0 & 0 & 0.893 \\
\hline 1 & 0 & 1 & 1 \\
\hline 1 & 0 & 2 & 1.05 \\
\hline 1 & 1 & 0 & 0.45 \\
\hline 1 & 1 & 1 & 0.96 \\
\hline 1 & 1 & 2 & 4.052 \\
\hline
\end{tabular}

\section{Results and Discussion}

The results of simulations for three different co-exposure scenarios are presented graphically (Fig.2 10). These results provide us the platform for viewing the effect of the interaction between these elements on their respective tissue concentrations. They also enable us to quantify the modulation in the tissue concentrations by comparing modulated and unmodulated tissue concentrations. The first set of graphs (Fig.2 4) show the combined effect of exposure to mercury $(0.231 \mu \mathrm{mols} / \mathrm{kg} / \mathrm{day})$ and lead $(0.241 \mu \mathrm{mols} / \mathrm{kg} / \mathrm{day})$ on the concentration of the elements (mercury, lead and selenium) in an individual with low selenium intake $(0.380$ $\mu$ mols $/ \mathrm{kg} / \mathrm{day})$. The combined dose of mercury and lead in this case was categorized as low $(<0.5 \mu \mathrm{mols} /$ $\mathrm{kg} / \mathrm{day}$ ). Comparing Fig. 2a and Fig. 2b, shows that the concentration of mercury in the liver, kidney, brain, richly perfused tissues, and slowly perfused tissues were modulated by factors of 2.01, 0.91, 1.5, 0.91, and 0.90 respectively, while comparing Fig. 3a and Fig. 3b shows that the concentration of lead in the liver, kidney, brain, richly perfused tissues, and slowly perfused tissues were also modulated by factors of 2.01, 0.91, 1.5, 0.91 , and 0.90 respectively. These factors are consistent with the modification factors in the respective truth tables. On the other hand, comparing Fig. 4a and Fig. 4b, shows that selenium molar concentration in these tissues were modulated by factors of $0.03,0.21,0.89,0.75$, and 0.75 , respectively.

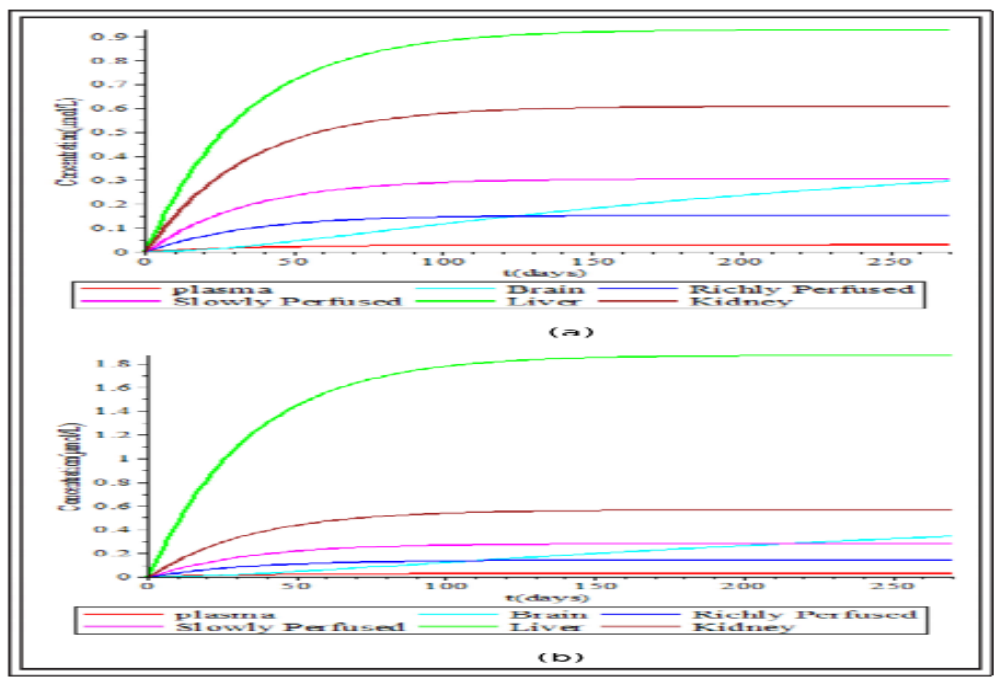

Figure 2. Effect of the interaction between mercury, lead, and selenium on mercury concentration: (a) Concentration profiles without interaction (b) modulated concentration profiles due to interaction. 


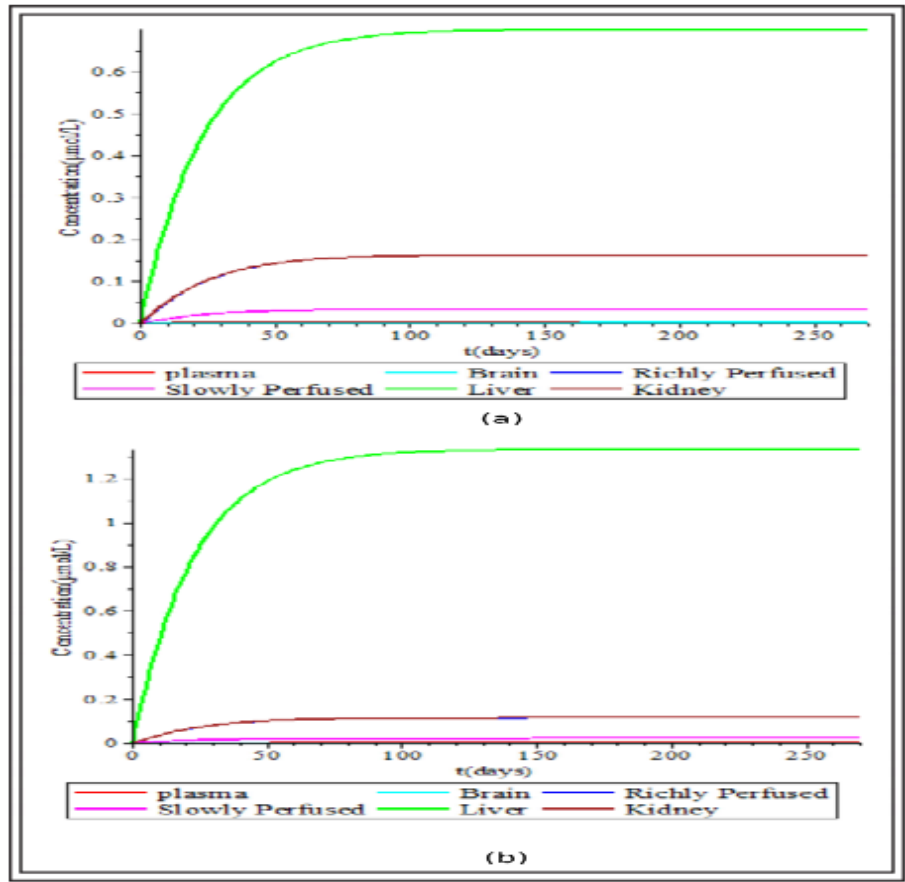

Figure 3. Effect of the interaction between mercury, lead, and selenium on lead concentration: (a) Concentration profiles without interaction (b) modulated concentration profiles due to interaction.

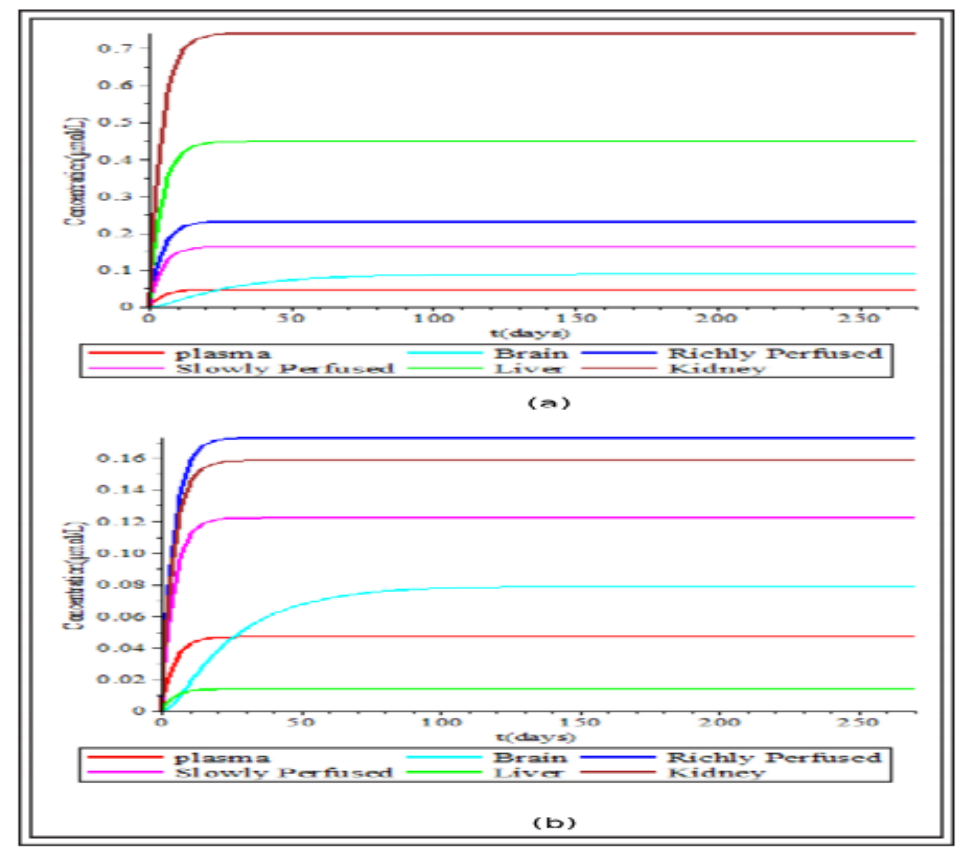

Figure 4. Effect of the interaction between mercury, lead, and selenium on selenium concentration: (a) Concentration profiles without interaction (b) modulated concentration profiles due to interaction.

The second set of results (Fig.5, 6, 7) are simulations illustrating the combined effect of exposure to mercury $(0.462 \mu \mathrm{mols} / \mathrm{kg} / \mathrm{day})$ and lead $(0.241 \mu \mathrm{mols} / \mathrm{kg} / \mathrm{day})$ on the concentration of the respective elements (mercury, lead and selenium) in various tissues of the individual, when selenium intake was $0.380 \mu$ mols/ $\mathrm{kg} /$ day (categorized as low). In this case, the combined dose of mercury and lead was $>0.5 \mu \mathrm{mols} / \mathrm{kg} / \mathrm{day}$, hence it was categorized as high. The result shows that the concentration of mercury and lead were modified by factors of $1.51,0.68,1.28,1.45$, and 1.45 in the liver, kidney, brain, richly perfused tissues and slowly perfused tissues, respectively (Fig.5 and 6). The concentration of selenium, on the other hand, were modulated by factors of 0.05 , $0.30,0.45,0.60$, and 0.60 respectively in these tissues (Fig.7). 


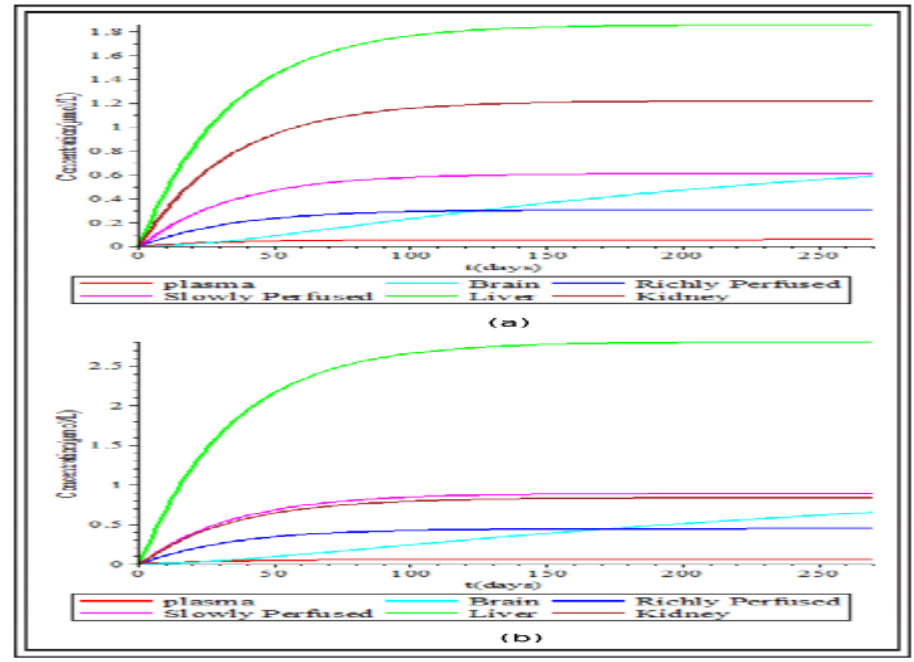

Figure 5. Effect of the interaction between mercury, lead, and selenium on mercury concentration: (a) Concentration profiles without interaction (b) Modulated concentration profiles due to interaction.

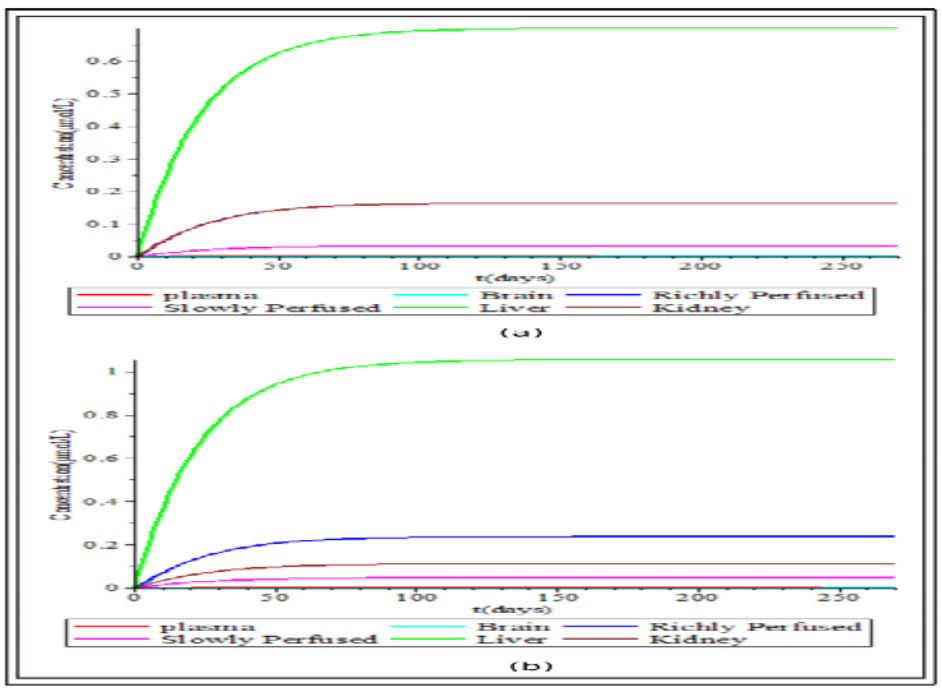

Figure 6. Effect of the interaction between mercury, lead, and selenium on lead concentration: (a) Concentration profiles without interaction (b) Modulated concentration profiles due to interaction.

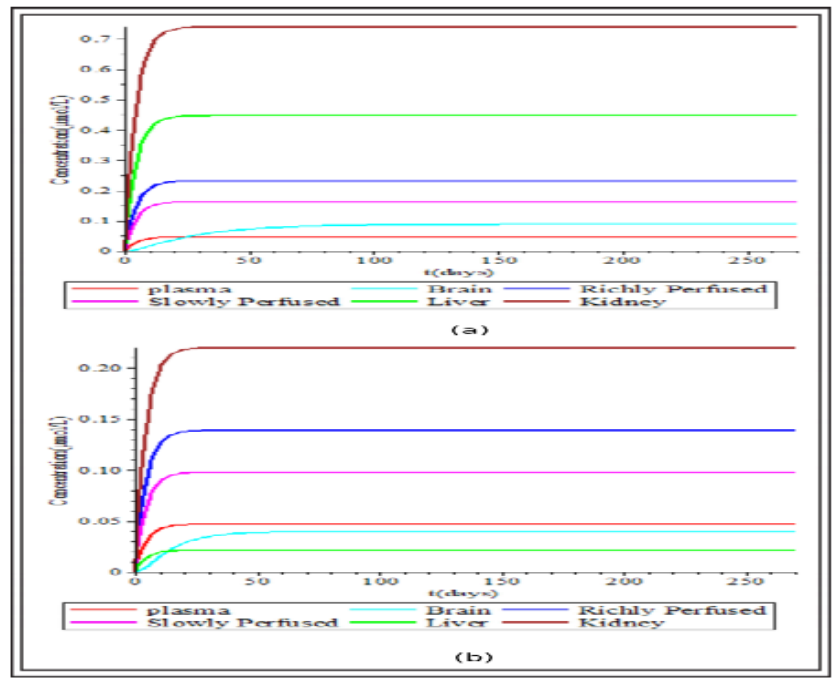

Figure 7. Effect of the interaction between mercury, lead, and selenium on selenium concentration: (a) Concentration profiles without interaction (b) Modulated concentration profiles due to interaction. 
Depicted in Fig.8, 9, and 10 are simulations showing the modulating effect of the interaction between these elements when selenium intake was adequate while the combined dose of lead and mercury was categorized as high. Fig. 8 and 9 show that with adequate selenium intake there was no modulation in the concentration of lead and mercury in all tissues modeled. However, Fig. 10 shows that when the combined dose of mercury and lead was categorized as high and selenium intake was adequate, the selenium concentration in the liver, kidney, brain, richly perfused tissues and slowly perfused tissues were modulated by factors of 0.82 , $2.89,0.96,0.64$ and 0.64 , respectively.

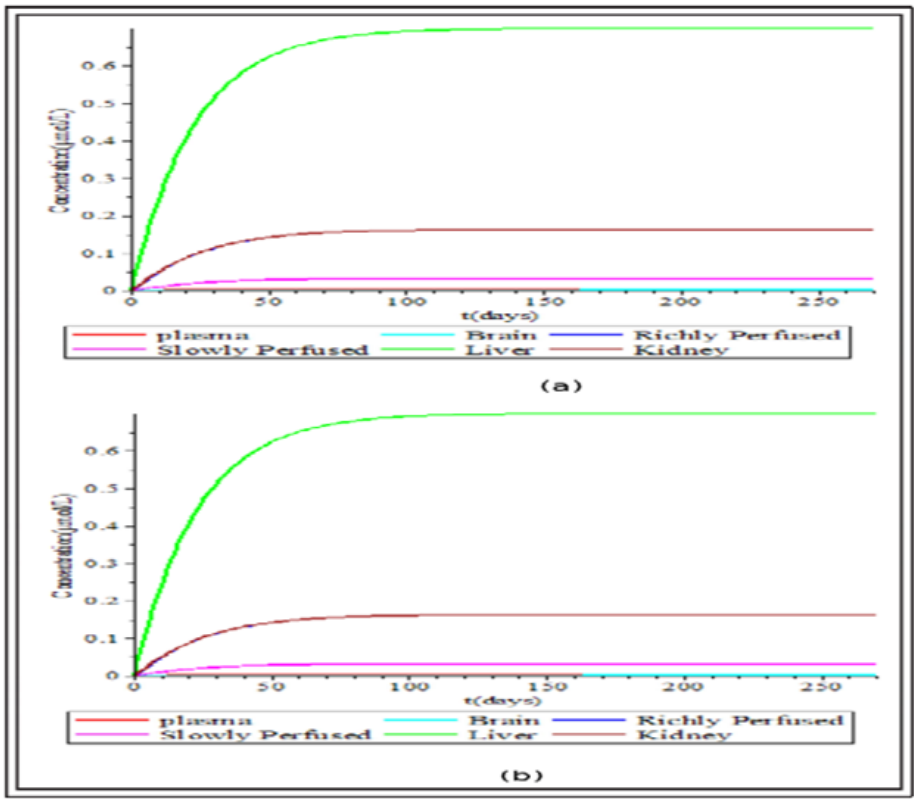

Figure 8. Effect of the interaction between mercury, lead, and selenium on lead concentration: (a) Concentration profiles without interaction (b) Modulated concentration profiles due to interaction.

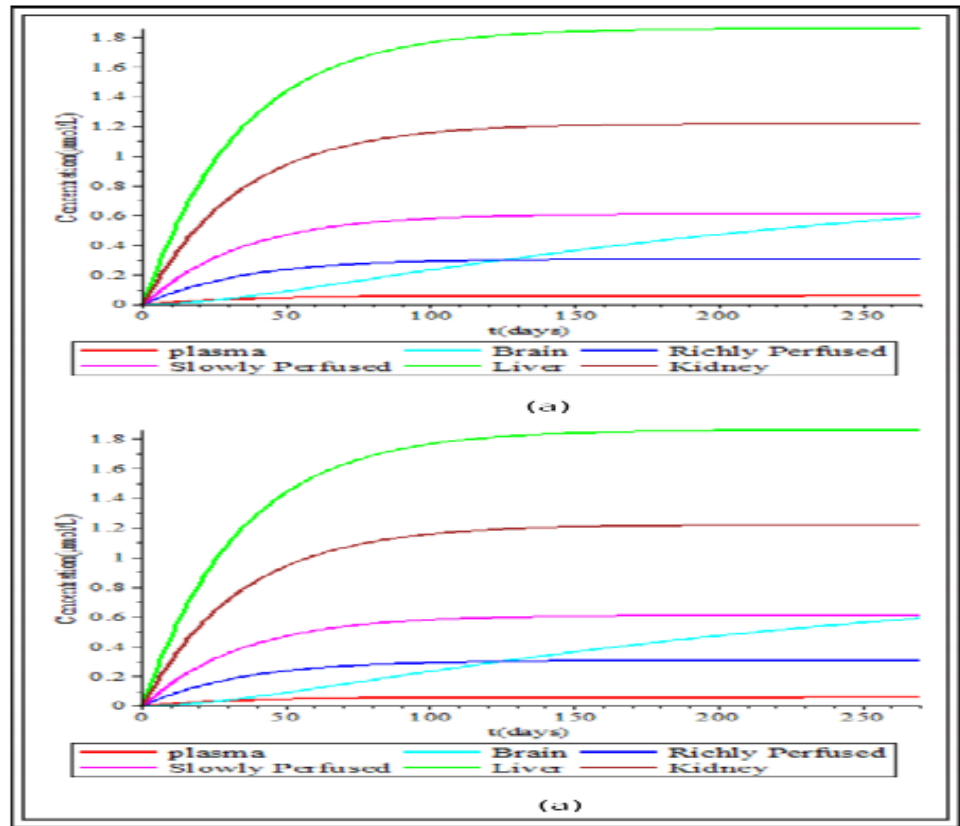

Figure 9. Effect of the interaction between mercury, lead, and selenium on mercury concentration: (a) Concentration profiles without interaction (b) Modulated concentration profiles due to interaction. 


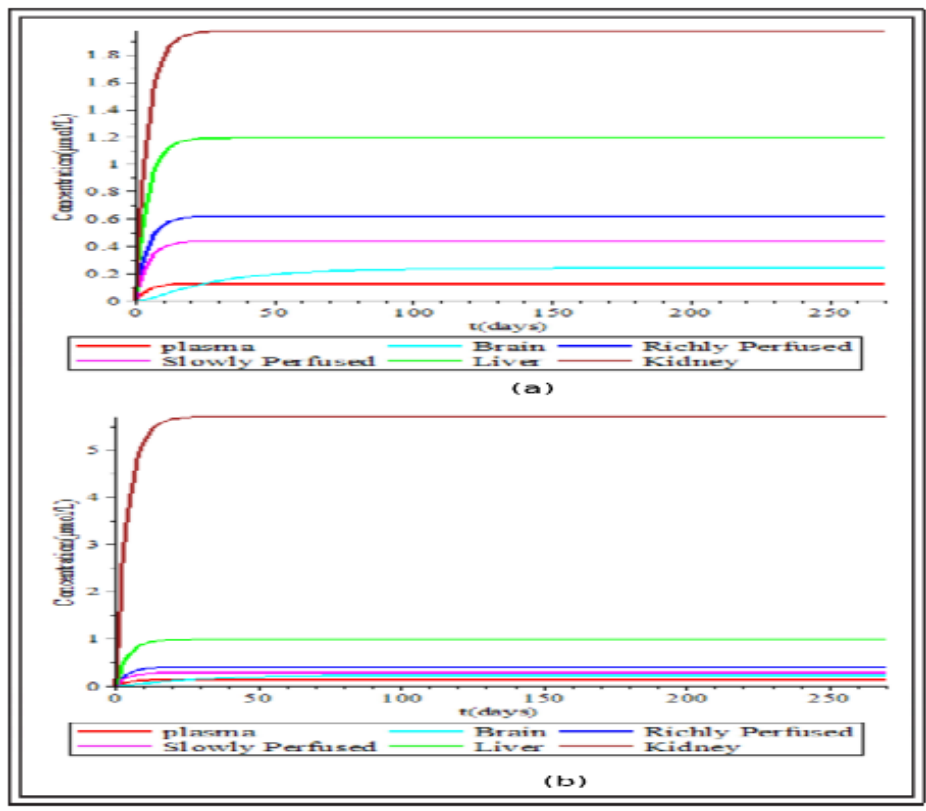

Figure 10. Effect of the interaction between mercury, lead, and selenium on selenium concentration: (a) Concentration profiles without interaction (b) Modulated concentration profiles due to interaction.

\section{Conclusion}

This study has led to the development of a human physiologically-based biokinetic model for the mixture of lead, mercury and selenium. The mixture model developed was capable of simulating simultaneously, under various co-exposure scenarios, the absorption, distribution, metabolism and elimination (ADME) properties of these elements in a number of human tissues. The model also demonstrated its ability to simulate the modulation in the respective tissue concentrations, resulting from the interaction between these elements. These modulations were shown to be primarily dependent on the categorization of the respective doses of lead, mercury and selenium. It is hoped that this model could be a good tool in the health risk assessment of mercury and lead.

\section{References}

[1] M. E. Andersen. Toxicokinetic modelling and its application in chemical risk. Toxicology Letters, $138,9-27$.

[2] US Air Force. Physiologically-Based Pharmacokinetic/Toxicokinetic Modeling In Risk Assessment. Technical report, United States Air Force Research Laboratory, 2005.

[3] US Environmental Protection Agency. Approaches for the Application of Physiologically Based Pharmacokinetic (PBPK) Models and Supporting Data in Risk Assessment. National Center for Environmental Assessment, Washington, DC; EPA/600/R-05/043F, 2006.

[4] M. Mumtaz, J. Fisher, B. Blount, and P. Ruiz. Application of Physiologically Based Pharmacokinetic Models in Chemical Risk Assessment. Journal of toxicology, 2012, 1-11, 2012.

[5] M. E. Andersen, H. J. Clewell, M. L. Gargas, F. A. Smith, and R. H. Reitz. Physiologically based pharmacokinetics and the risk assessment process for methylene chloride. Toxicology and Applied Pharmacology, 87, 185-205, 1987.

[6] P. Ruiz, M. Ray, J. Fisher, and M. Muntaz. Development of a Human Physiologically based Pharmacokinetic (PBPK) Toolkit for Environmental Pollutants. International Journal of Molecular Science, 7469-7480, 2011.

[7] J. L. Campbell Jr, R. A. Clewell, P. R. Gentry, M. E. Andersen, and H. J Clewell III. Physiologically Based Pharmacokinetic/Toxicokinetic Modeling. In Computational Toxicology, Chapter 18. Springer Science + Business Media, LLC, 2012.

[8] K. Krishnan, H.J. Clewell III, and M. E. Andersen. Physiologically Based Pharmacokinetic Analysis of Simple Mixtures. Environmental Health Perspective, 102 (9), 151-155, 1994.

[9] S. Hadad, and K. Krishnan. Physiological modeling of Toxicokinetic Interactions: Implications for Mixture Risk Assessment. Environmental Health Perspectives, 106 (6), 1377-1384, 1998.

[10] I Silins, and J. Högberg. Combined Toxic Exposures and Human Health: Biomakers of Exposure and Effect. International Journal of Environmental Research and Health, 8, 629-647, 2011.

[11] M. L. A. Curvin-Aralar, and R. W. Furness. Mercury and Selenium Interaction: A Review. Ecotoxicology and Environmental Safety, 21, 348-364, 1991.

[12] L. J. Raymond, and N. V. C. Ralston. Mercury:Selenium Interactions and Health Implications. Seychelles Medical and Dental Journal, 7(1), 72-77, 2004.

[13] S. J. S. Flora, M. Mittal, and A. Mehta. Heavy Metal Induced Oxidative Stress and its Possible Reversal by Chelation Therapy. Indian Journal of Medical Research, 128, 501-523, 2008.

[14] V. C. Ralston, and L. J. Raymond. JV Task 96-Phase 2-Investigating the Importance of the MercurySelenium Interaction. Technical report, University of North Dakota, 2008.

[15] N. V. C. Ralston, C. R. Ralston. J. L. Blackwell III, L. J. Raymond. Dietary and Tissue Selenium in Relation to Methylmercury Toxicity. NeuroToxicology, 2008. 
[16] J. Kaneko, and P. Bartram. Mercury in Seafood: Is Hawaii Seafood Safe? Technical report, National Oceanographic and Atmospheric Administration, U.S. Department of Commerce, 2009.

[17] K. Krishnan, H. J. Clewell III, and M. E. Anderson. (1994). Physiologically Based Pharmacokinetic Analysis of Simple Mixtures. Environmental Health Perspective, 102 (9), 151-155, 1994.

[18] D. D. Maza, and J. O. Ojo. Development of Human PBBK Models for Mixtures: Binary Mixtures of Mercury/Selenium, and Lead/Selenium. Ife Journal of Science, 18 (4), 1019-1040, 2016. 